\title{
Urbanization and heterogeneous surface warming in eastern China
}

\author{
WU Kai \& YANG XiuQun* \\ Institute for Climate and Global Change Research, School of Atmospheric Sciences, Nanjing University, Nanjing 210093, China
}

Received September 11, 2012; accepted November 13, 2012; published online January 14, 2013

\begin{abstract}
With the homogeneity-adjusted surface air temperature (SAT) data at 312 stations in eastern China for 1979-2008 and the Defense Meteorological Satellite Program/Operational Linescan System (DMSP/OLS) nighttime light data, the spatial heterogeneities of the SAT trends on different scales are detected with a spatial filtering (i.e. moving spatial anomaly) method, and the impact of urbanization in eastern China on surface warming is analyzed. Results show that the urbanization can induce a remarkable summer warming in Yangtze River Delta (YRD) city cluster region and a winter warming in Beijing-Tianjin-Hebei (BTH) city cluster region. The YRD warming in summer primarily results from the significant increasing of maximum temperature, with an estimated urban warming rate at $0.132-0.250^{\circ} \mathrm{C}$ per decade, accounting for $36 \%-68 \%$ of the total regional warming. The BTH warming in winter is primarily due to the remarkable increasing of minimum temperature, with an estimated urban warming rate at $0.102-0.214^{\circ} \mathrm{C}$ per decade, accounting for $12 \%-24 \%$ of the total regional warming. The temporal-spatial differences of urban warming effect may be attributed to the variation of regional climatic background and the change of anthropogenic heat release.
\end{abstract}

heterogeneous surface warming, urbanization, surface air temperature, maximum temperature, minimum temperature, eastern China

Citation: $\quad$ Wu K, Yang X Q. Urbanization and heterogeneous surface warming in eastern China. Chin Sci Bull, 2013, 58: 1363-1373, doi: 10.1007/s11434-012-5627-8

Surface warming over recent five decades is attributed to natural climate change and anthropogenic forcing. The anthropogenic forcing mainly includes the emissions of greenhouse gases (GHG) and aerosols, as well as the land use/ cover change (LUCC) [1]. Relative to the enhanced greenhouse effect, however, the climatic effect of LUCC has not been drawn sufficient attention. The urbanization is one of the extreme processes in LUCC [2]. It can alter surface vegetation distribution, induce regional climate change and increase uncertainty in future climate projection [3]. Moreover, large-scale urbanization can affect regional surface energy and water balance [4], and thus may intensify the frequency of extreme weather/climate events. Since both GHG and urbanization tend to increase the surface air temperature (SAT), it is quite difficult to estimate the relative contribution of either effect to the surface warming [5].

A variety of methods have been adopted to detect the climatic effect of urbanization. The most conventional and

*Corresponding author (email: xqyang@nju.edu.cn) direct method is the so-called urban-minus-rural (UMR) method in which the SAT at urban and rural sites is contrasted. The key of this method depends on whether or not those sites or stations can be objectively classified. In general, such a classification utilizes either population data [6-17] or satellite data (such as nighttime light imagery and land cover dataset) [18-23] as well as the geographic location of the stations. In addition, Empirical Orthogonal Function (EOF) [24,25], Principal Component Analysis (PCA) [26,27] and station metadata [28] can also be applied to define reference or rural stations. By comparing the difference between urban and reference (rural) stations, the impact of urbanization on SAT can be estimated.

Although the UMR method can directly detect the climatic effect of urbanization, it is sensitively dependent of classification of stations and sampling, which would increase the uncertainty of results [5]. Kalnay and Cai [5] proposed a new method to assess the impact of urbanization and LUCC on climate by computing the difference of SAT trends between observation and reanalysis, i.e. the so-called 
observation-minus-reanalysis (OMR) method. The OMR method is based on the fact that the reanalysis data did not assimilate observed surface information. This method does provide some signatures consistent with the distribution of underlying surface properties [22,29-36]. However, whether or not the OMR fully represents the impact of LUCC is still controversial [37,38].

China has been experiencing rapid economic growth and intensive urbanization since the 1980s. Due to close ties in social and economic aspects, single cities have expanded to form distinctive city clusters in eastern China, such as the Beijing-Tianjin-Hebei (BTH), Yangtze River Delta (YRD) and Pearl River Delta (PRD) city clusters. Meanwhile, the climatic effect of urbanization has drawn more and more attention. Some previous studies indicated that urbanization has little impact on regional warming [7,13,26,27]. However, recent investigations have suggested that the urbanization process can not only increase the local daily temperature, but also play an essential role in regional climate change [6,9,12,14-17,20-24,28-30,35,36]. Using the OMR method, Zhou et al. [29] and Zhang et al. [30] found that the urbanization exerts a significant influence on temperature trends in eastern China. Their results also revealed that the urbanization process is likely to enhance the increasing trend of the minimum temperature while imposing a relatively small influence on the maximum temperature, thus decreasing the diurnal temperature range. On the basis of the UMR method, Du et al. [20] indicated that the warming rate brought about by the urbanization in the YRD region is $0.069^{\circ} \mathrm{C}$ per decade and the effect of urban heat island is more significant in summer than winter. Zhang et al. [39] performed a series of numerical simulations to show that the urban heat island effect in the YRD region features obvious diurnal variation, thus affects the structure and development of urban boundary layer. With records at 282 stations in northern China, Ren et al. [15] determined that the urban warming rate is $0.11^{\circ} \mathrm{C}$ per decade, which accounts for $37.9 \%$ of the overall regional warming in northern China. However, they found that the urban heat island effect is more remarkable in winter than summer, unlike that in the YRD region [20]. Ding and Dai [40] and Ren et al. [14,15] argued that urbanization is one of major sources for uncertainties in climate change analysis. Yang et al. [22] showed that the contribution of urbanization to the surface warming appears to be comparable to that of GHG in the YRD region.

There are numerous studies to have focused on the impact of urbanization on the SAT change in China (Table 1). However, there are considerable inconsistencies that still exist in the aforementioned results. Such inconsistencies may be attributed to the differences of time period, regional span and analysis method. Another important issue in the analysis of station observations is the homogeneity of data. Homogeneity-adjusted data can mitigate the influence of subjective factors on temperature records and objectively reflect climate change [41-44]. Besides, the inconsistent conclusions in the seasonal and diurnal variations of urbanization effect still exist. With a homogeneity-adjusted dataset, the objective of this work is to estimate the effect of urbanization on the SAT change in eastern China, detect the seasonal variation of urban warming in different regions, and analyze the impact of urbanization on maximum and minimum temperatures. Therefore, to assess the climatic effect of urbanization is of great significance for further understanding the relationship between urban development and extreme climate change.

\section{Data sources and homogeneity adjustment}

Surface climate/weather observation network in China consists of three levels: 160 National Reference Climate Stations (RCS, hourly observation), 600 National Basic Weather Stations (BWS, four times a day) and 1800 Ordinary Weather Stations (OWS, daily observation). The RCS and BWS are referred to as national stations, totally 760 sites. As indicated by $\mathrm{Wu}$ [45], 70\%-80\% of the national stations have been migrated for several times since the 1950s. Therefore, it is necessary to perform the homogeneity adjustment of station records before analyzing those records [45-47].

Methods for detecting and adjusting homogeneity in temperature series have been studied [41-43]. Li et al. [41] used two-phase regression homogeneity test approach to correct the SAT records in China and released the first China Homogenized Historical Temperature (CHHT, version 1.0) dataset. Afterward, Li and Yan [43] applied Multiple Analysis of Series for Homogenization (MASH) to adjust the daily temperature series (1960-2008) at 549 stations in China. The MASH method has a rigorous mathematical foundation and has been developed into mature software program. Compared with the aforementioned method [41], The MASH method can objectively correct the inhomogeneity without station metadata, and especially can detect deviation arising from the alteration from manual to automatic observation systems [48].

The homogeneity-adjusted daily mean SAT data [43] is used in this study. Besides, nighttime light data obtained from the Defense Meteorological Satellite Program/Operational Linescan System (DMSP/OLS) is applied to classify stations into different types. The version 4 stable nighttime light products with $1 \mathrm{~km}$ spatial resolution were downloaded from the National Geophysical Data Center (http://www. ngdc.noaa.gov/dmsp/downloadV4composites.html). For its unique low-light imaging capacity, the nighttime light imagery can not only be used as the characteristic index in the analysis of urbanization effect, but also meet the needs of detection in human activities [49,50]. In terms of Zhou et al. [29] and $\mathrm{Hu}$ et al. [35], the urbanization process in China primarily started around 1979. Therefore, observed data during the period from 1979 to 2008 in eastern China 


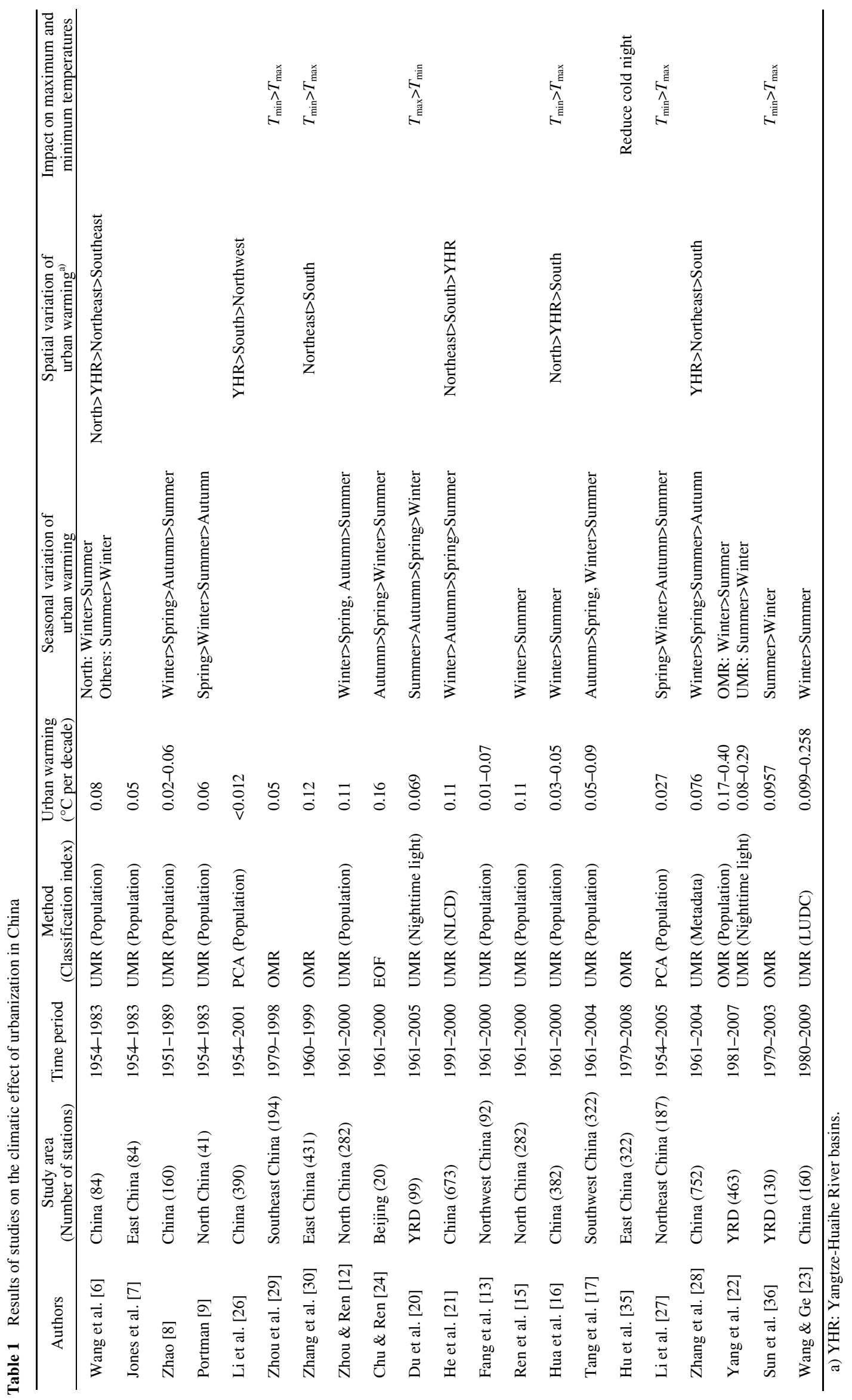


$\left(15^{\circ}-54^{\circ} \mathrm{N}, 110^{\circ}-136^{\circ} \mathrm{E}\right)$ is used in the following analysis.

\section{Methods}

\subsection{Time series and linear trends}

The homogeneity-adjusted SAT data at 312 stations located in eastern China with continuous observation during the analysis period are selected from 549 stations. Four seasonal mean temperatures are defined by calculating the average of each three-month: December-to-February (winter), Marchto-May (spring), June-to-August (summer) and Septemberto-November (autumn). Seasonal mean, maximum and minimum temperatures for each season are computed for the period from 1979 to 2008. Their linear trends can be estimated by using ordinary least squares. Meanwhile, the $t$-test is applied to examine the statistical significance of the linear trends.

\subsection{Spatial filtering and moving spatial anomaly}

A spatial filtering method in this study is proposed to identify the impact of climatic forcing with different spatial scales on the SAT change. Concretely, for each station a moving spatial anomaly (MSA) is defined as the departure from an average over a region with center at the station. Then, the moving spatial anomalies for all the stations are calculated when the region is slid. Since such a region is moving, it acts as a filtering window, and thus the MSA is a spatially-filtered component. By altering the size of the filtering window, the spatial heterogeneities on different spatial scales are detected.

In this study, the spatial filtering (i.e. MSA) method is applied to the linear trend of the SAT change. In order to isolate the heterogeneous climatic effect of the urbanization, the size of filtering window is empirically taken as $8^{\circ} \times 8^{\circ}$, $12^{\circ} \times 12^{\circ}$ and $16^{\circ} \times 16^{\circ}$, respectively, combined with nighttime light imagery and station distribution (Figure 1). Assume that the SAT change on the spatial scales larger than the size of the filtering window is attributed to large scale climatic forcing. Then the spatial heterogeneity of the SAT trends indicated with the MSA calculated above reflects the impact of regional climatic forcing such as urbanization, LUCC and anthropogenic heat release on the SAT change.

\subsection{Classification of stations and definition of urban warming}

Figure 1 shows the DMSP/OLS nighttime light imagery in 2008 and the distribution of stations. With the nighttime light data, the location of stations and the related study results [51-53], an urban station is defined when the nighttime light value is no less than 55 and a non-urban station is defined when the value is less than 55. In terms of such a classification of stations, an urban warming rate can be estimated for

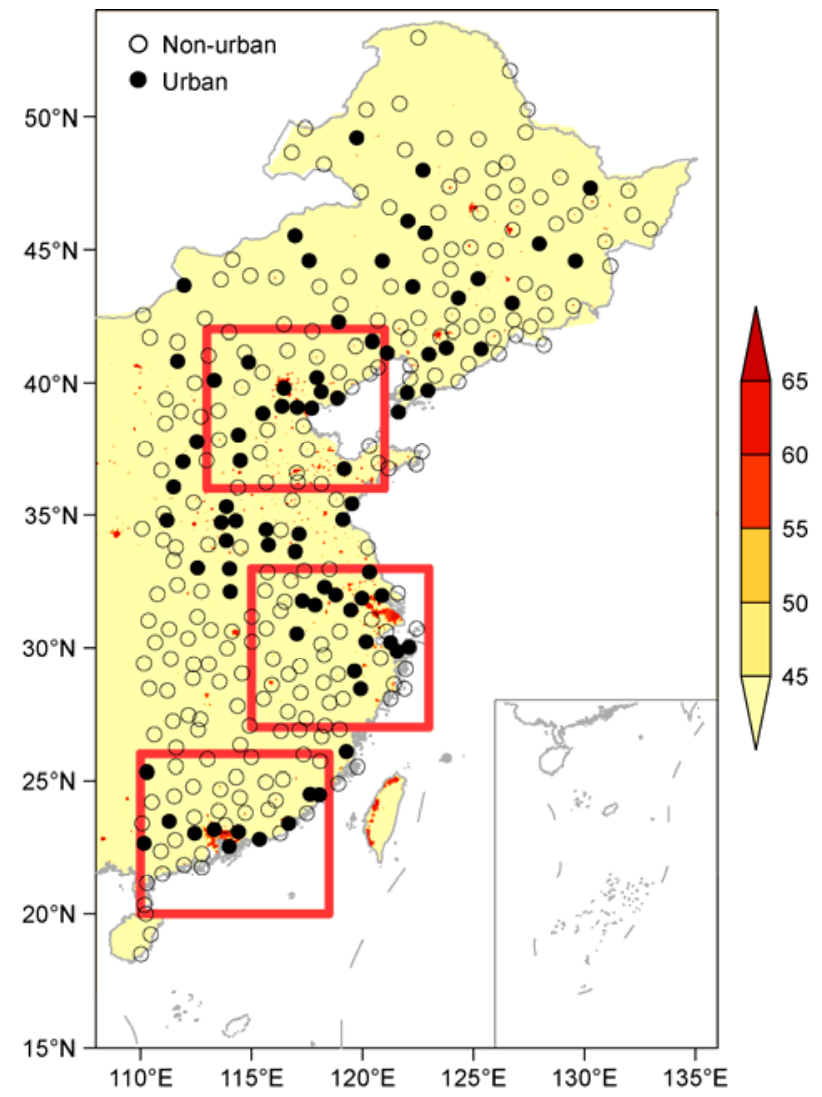

Figure 1 DMSP/OLS nighttime light imagery in 2008 (shaded) and distribution of stations for two categories (urban versus non-urban) (circles). Red boxes indicate three representative regions associated with the Beijing-Tianjin-Hebei (BTH), Yangtze River Delta (YRD) and Pearl River Delta (PRD) city clusters in China, respectively.

three major city clusters (red boxes in Figure 1) in eastern China, respectively. For each city cluster region, the urban warming rate $\left(U_{n}\right)$ can be expressed as

$$
U_{n}=\frac{1}{n} \sum_{i=1}^{n} a_{i},
$$

where $a_{i}$ represents the MSA of the SAT trend and $n$ is the number of urban stations within the region. Meanwhile, a regional total warming rate $\left(R_{m}\right)$ is defined as

$$
R_{m}=\frac{1}{m} \sum_{i=1}^{m} b_{i}
$$

where $b_{i}$ represents the total SAT trend and $m$ is the number of all the stations (including urban and non-urban stations) within the region. Thus, the contribution rate $\left(U_{r}\right)$ of urbanization to the regional total warming is calculated as

$$
U_{r}=\frac{U_{n}}{R_{m}} \times 100 \% .
$$

By analyzing $U_{n}$ and $U_{r}$ in the three city cluster regions, the impact of urbanization on regional climate change in eastern China can be estimated. 


\section{Results}

\subsection{Temporal-spatial variations of SAT trends}

Figure 2 shows the spatial distribution of seasonal mean SAT trends in eastern China. Warming signals can be observed obviously in each season, and the annual mean warming rate is about $0.5^{\circ} \mathrm{C}$ per decade. This value is higher than that estimated by Ding et al. [54], which may be due to the increased warming during last three decades in eastern China. Moreover, the large-scale warming exhibits considerable temporal-spatial variations. The warming is more spatially heterogeneous in summer (Figure 2(b)) and winter (Figure 2(d)), while relatively homogeneous in spring (Figure 2(a)) and autumn (Figure 2(c)). Overall, the warming rates are larger in spring and autumn than winter and summer (Table 2). The difference of warming rate between urban and non-urban stations (Table 2) may reflect the cli- matic effect of urbanization. It is found that the urban warming also features an obvious seasonal variation. The urbanization effect appears considerably remarkable in winter and spring, but relatively weak in autumn and summer. With the difference, the annual mean temperature change caused by urbanization is estimated to be $0.057^{\circ} \mathrm{C}$ per decade, accounting for $11.4 \%$ of total averaged warming in whole eastern China.

\subsection{Spatial heterogeneities of SAT trends on different scales}

Since the SAT trends are characterized by obvious spatial heterogeneity in summer and winter, the spatial filtering (i.e., MSA) method described in section 2 is employed to extract the effect of regional climatic forcing on seasonal mean SAT change in these two seasons. Figure 3 demonstrates the spatial distributions of the MSA for seasonal
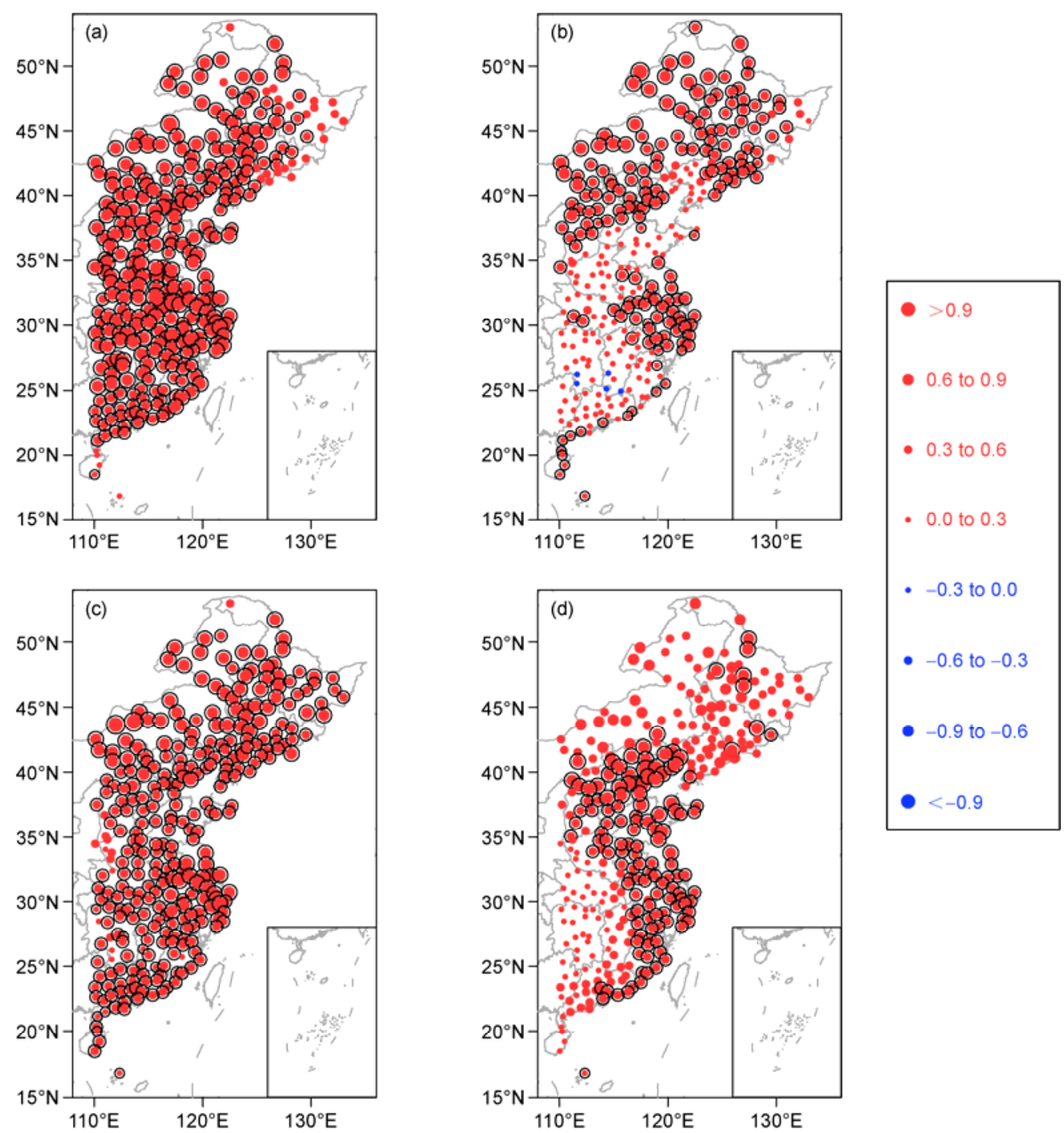

Figure 2 Seasonal mean surface air temperature trends for (a) spring, (b) summer, (c) autumn and (d) winter during 1979-2008. The red solid circles denote the value of the trends, while the black open circles denote that trend is significant at $95 \%$ confidence level (Unit: ${ }^{\circ} \mathrm{C}$ per decade). 
Table 2 Regional average of seasonal and annual mean surface air temperature trends during $1979-2008^{\text {a) }}$ (Unit: ${ }^{\circ} \mathrm{C}$ per decade)

\begin{tabular}{llllll}
\hline & Annual & Spring & Summer & Autumn & Winter \\
\hline All stations & 0.500 & 0.644 & 0.324 & 0.519 & 0.492 \\
Urban & 0.542 & 0.696 & 0.355 & 0.551 & 0.547 \\
Non-urban & 0.485 & 0.625 & 0.313 & 0.508 & 0.472 \\
Difference & $0.057^{* *}$ & $0.071^{* *}$ & 0.042 & $0.043^{*}$ & $0.075^{* *}$ \\
\hline
\end{tabular}

a) Statistical significance at $0.05(*)$ and $0.01(* *)$ levels.
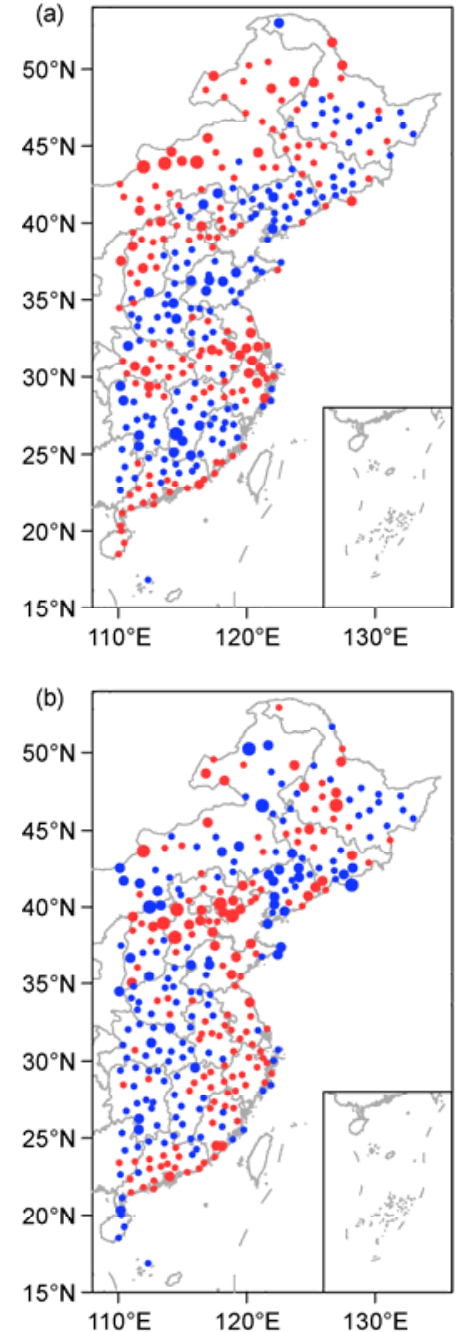
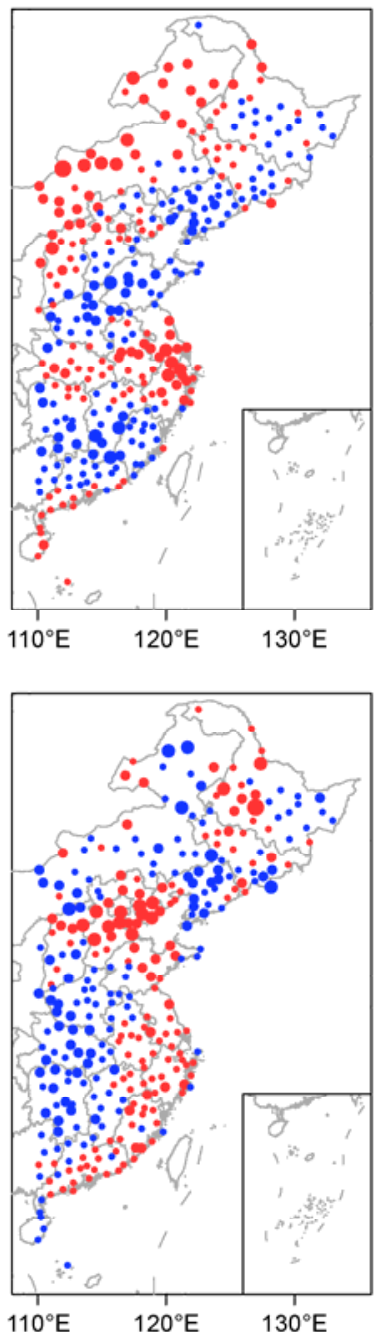

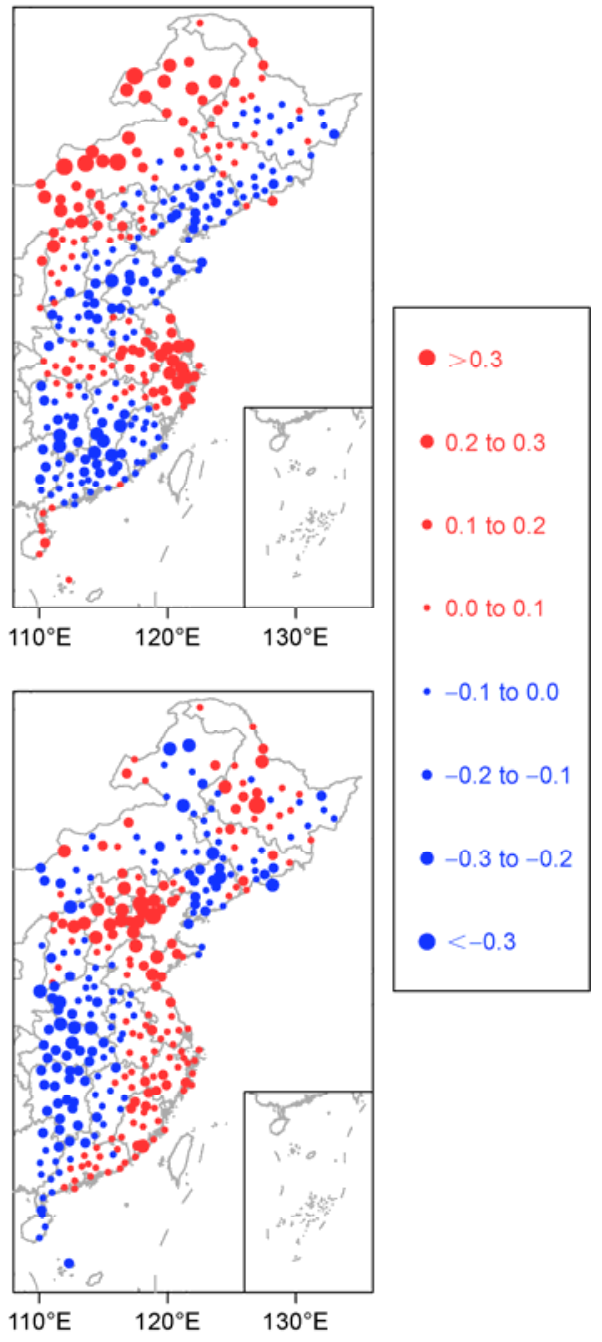

Figure 3 Moving spatial anomalies of seasonal mean surface air temperature trends for three types of filtering window sizes $\left(\mathrm{I}\right.$ : $8^{\circ} \times 8^{\circ}$, II: $12^{\circ} \times 12^{\circ}$, III: $16^{\circ} \times 16^{\circ}$ ) for (a) summer and (b) winter (Unit: ${ }^{\circ} \mathrm{C}$ per decade).

mean SAT trends on three sizes of filtering windows. It is evident that although warming signal becomes more obvious with the expansion of filtering window, the spatial patterns roughly keep unchanged. In summer (Figure 3(a)), the remarkable warming primarily confines to the YRD and eastern Inner-Mongolian regions. In winter (Figure 3(b)), the significant warming mainly locates in the BTH region. The increasing of seasonal mean temperatures in YRD and BTH regions may result from the continuing urbanization process, and that in eastern Inner-Mongolia may be due to the desertification occurred over recent decades [35]. Temporal-spatial variations of urbanization effect in the YRD and BTH regions examined in this study are consistent with those in Du et al. [20] and Ren et al. [15].

In comparison with the MSA for seasonal mean SAT trends in Figure 3, Figures 4 and 5 illustrate the spatial distributions of the MSA for maximum and minimum temperature trends, respectively. It can be found that the urban warming in the YRD region in summer is primarily determined by the significant increasing of maximum temperature 

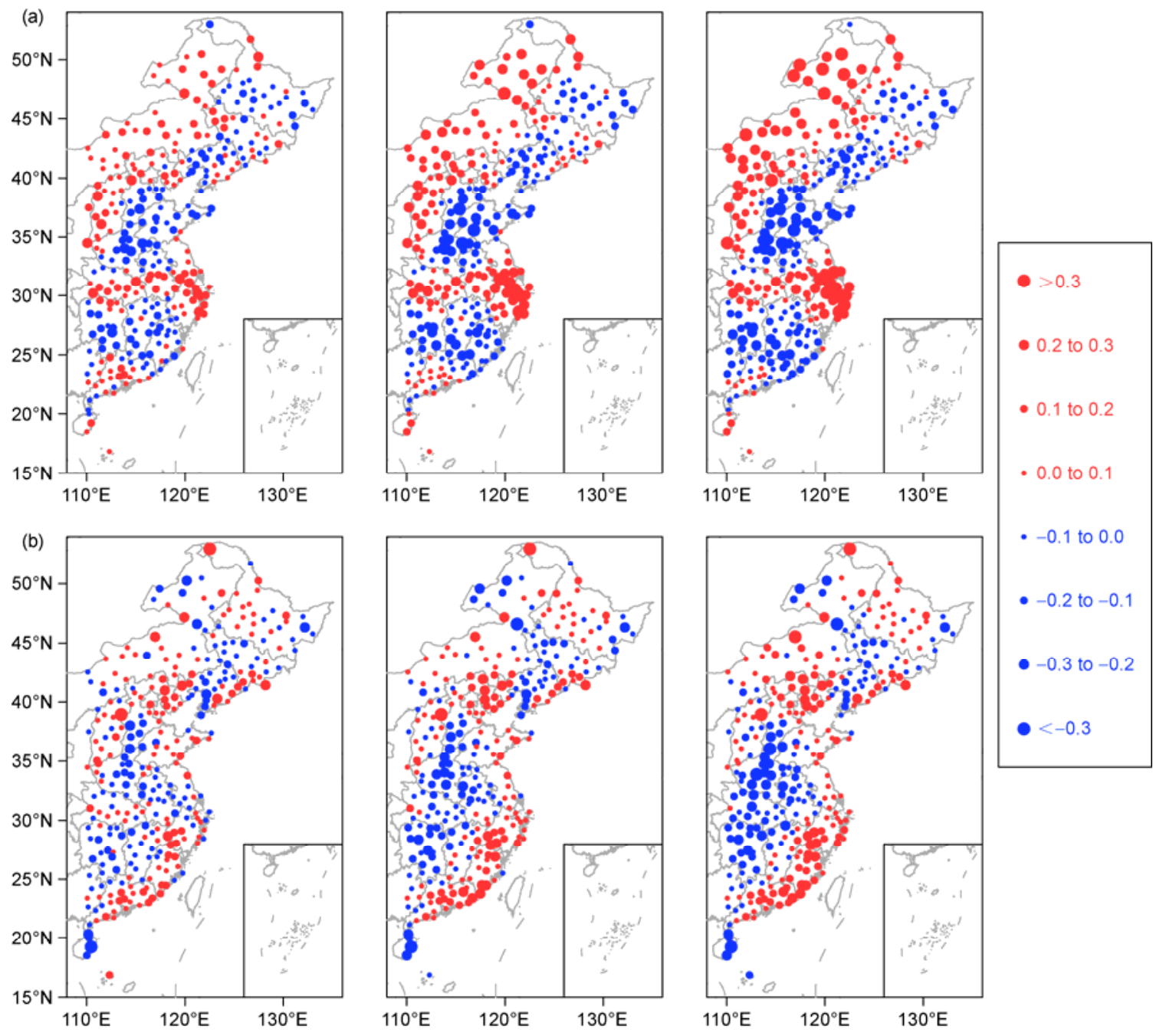

Figure 4 Same as Figure 3, but for the seasonal mean maximum temperature.

(Figure 4(a)), while that in the BTH region in winter is primarily due to the remarkable increasing of minimum temperature (Figure 5(b)). The temporal-spatial differences of urbanization effect may be related to the anthropogenic heat release [55]. Several studies have indicated that anthropogenic heat in the YRD region is mainly caused by the air conditioning refrigeration, which is more intensive during daytime than night and eventually can increase the daily maximum temperature in summer [56,57]. Conversely, anthropogenic heat in the $\mathrm{BTH}$ region is primarily caused by winter heating that is more intensive during night, which favors the increasing of daily minimum temperature in winter [58-60]. Additionally, winter maximum temperature also has increased in some other regions of northern and southeastern China (Figure 4(b)). The reason for such occurrences requires further investigation.

\subsection{Urban warming and contribution rates}

In terms of eqs. (1)-(3), the urban warming rates together with their contribution to the total regional warming are computed for three filtering windows and for three city cluster regions in eastern China. Table 3 lists the maximal urban warming rate and its corresponding season for each filtering window and for each city cluster. With the expansion of the filtering window size, the maximal urban warming rate is increased. However, the corresponding season substantially keeps unchanged. Specifically, the urbanization in the BTH region has significant impact on the increasing of winter minimum temperature with an estimated urban warming rate at $0.102-0.214^{\circ} \mathrm{C}$ per decade, while the urbanization in the YRD region primarily affects the summer maximum temperature with an urban warming rate at $0.132-0.250^{\circ} \mathrm{C}$ per decade. Winter maximum temperature in the PRD region is also increased at a rate of 0.076$0.125^{\circ} \mathrm{C}$ per decade that may be attributed to the urbanization process. Among the three city cluster regions, the urbanization causes the most significant warming in the YRD region, while the PRD region undergoes the smallest urban warming. Table 4 lists the contribution rate of urbanization 

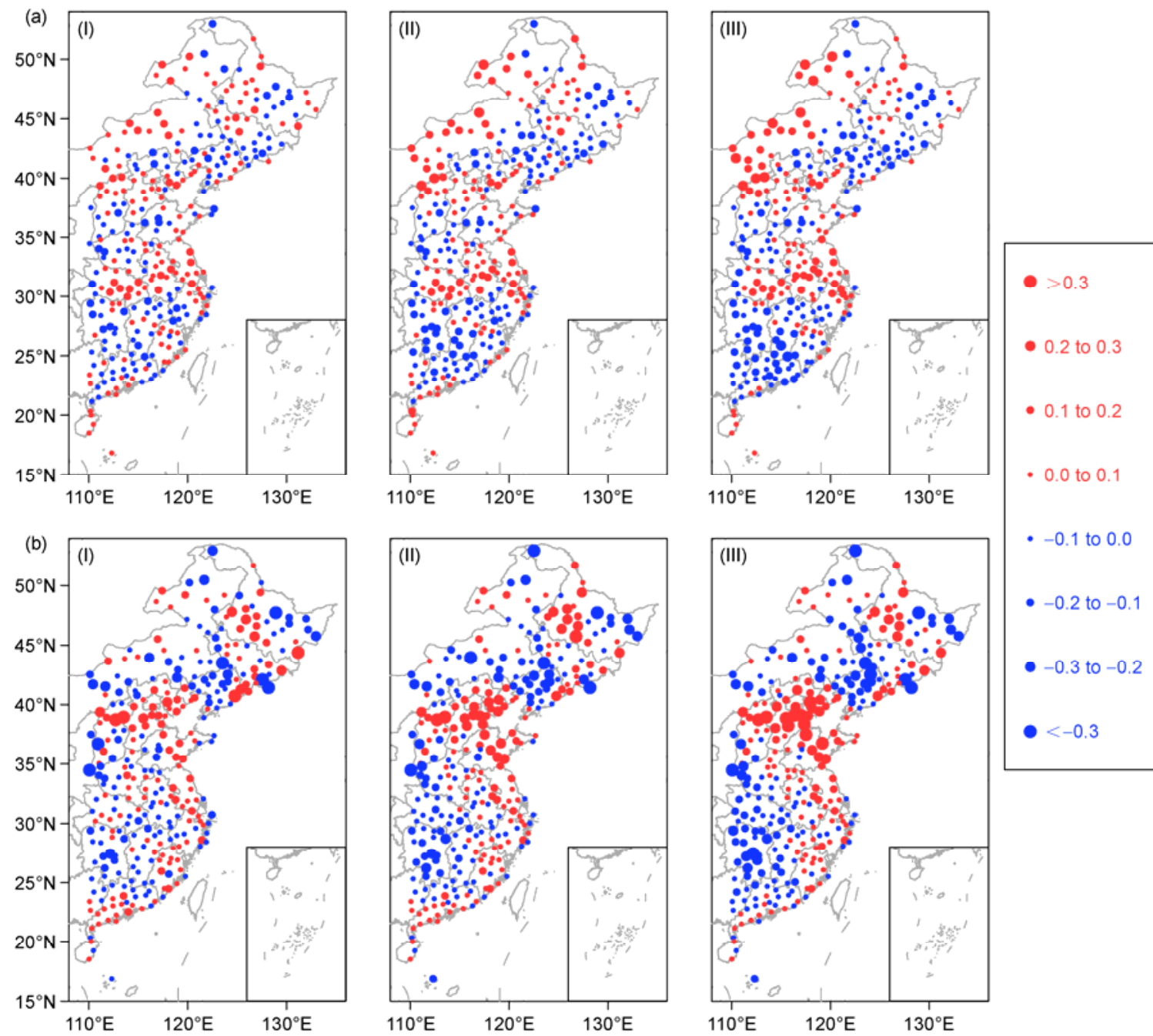

Figure 5 Same as in Figure 3, but for the seasonal mean minimum temperature.

Table 3 The maximal urban warming rate and its corresponding season (Unit: ${ }^{\circ} \mathrm{C}$ per decade)

\begin{tabular}{cccc}
\hline & $8^{\circ} \times 8^{\circ}$ & $12^{\circ} \times 12^{\circ}$ & $16^{\circ} \times 16^{\circ}$ \\
\hline \multirow{2}{*}{ BTH } & 0.102 & 0.165 & 0.214 \\
& Winter minimum temperature & Winter minimum temperature & Winter minimum temperature \\
YRD & 0.132 & 0.220 & 0.250 \\
& Summer maximum temperature & Summer maximum temperature & Summer maximum temperature \\
PRD & Winter maximum temperature & Winter maximum temperature & 0.125 \\
& & & Winter maximum temperature \\
\hline
\end{tabular}

Table 4 The contribution rate of urban warming and its corresponding season (Unit: \%)

\begin{tabular}{cccc}
\hline & $8^{\circ} \times 8^{\circ}$ & $12^{\circ} \times 12^{\circ}$ & $16^{\circ} \times 16^{\circ}$ \\
\hline \multirow{2}{*}{ BTH } & 12 & 19 & 24 \\
& Winter minimum temperature & Winter minimum temperature & Winter minimum temperature \\
YRD & 36 & 60 & 68 \\
\multirow{2}{*}{ PRD } & Summer maximum temperature & Summer maximum temperature & 28 \\
& Winter maximum temperature & Winter maximum temperature & Winter maximum temperature \\
\hline
\end{tabular}


to the total regional warming. It can be seen from the table that the urban warming accounts for $12 \%-24 \%, 36 \%-68 \%$ and $20 \%-32 \%$ of the total regional warming, respectively, in the BTH, YRD and PRD regions. Most strikingly, the contribution rate of urban warming in the YRD region is the largest and explains around half of the total regional warming. This suggests that the urbanization process does impose an essential impact on the regional climate change, especially in the YRD, a rapid urbanized region.

\section{Conclusions and discussion}

With homogeneity-adjusted SAT data at 312 stations in eastern China for 1979-2008, this study investigates spatial heterogeneities of the SAT trends and their association with the urbanization. Main conclusions are as follows.

(1) The SAT is characterized by a significant large-scale increasing trend from 1979 to 2008 in eastern China. The annual mean warming rate is estimated to be $0.5^{\circ} \mathrm{C}$ per decade. This large-scale warming features an obvious seasonal variation. The warming is more remarkable in spring and autumn than winter and summer. Meanwhile, the spatial pattern of the warming is more heterogeneous in summer and winter.

(2) The difference between urban and non-urban stations indicates that the warming rate of urbanization effect on annual mean temperature is $0.057^{\circ} \mathrm{C}$ per decade, accounting for $11.4 \%$ of total averaged warming in whole eastern China. Overall, the urbanization effect has obvious seasonal variation, which appears to be more significant in winter and spring, and relatively weak in autumn and summer.

(3) A spatial filtering (i.e. the MSA) method is proposed to detect the spatial heterogeneity of the SAT trends. The MSA distribution exhibits a significant summer urban warming in the YRD region and a significant winter urban warming in the BTH region. The YRD warming in summer primarily results from the increasing of maximum temperature while the BTH warming in winter is due to the increasing of minimum temperature.

(4) The urbanization in the BTH region has significant impact on the increasing of winter minimum temperature with an estimated urban warming rate at $0.102-0.214^{\circ} \mathrm{C}$ per decade, while the urbanization in the YRD region primarily affects the summer maximum temperature with an urban warming rate at $0.132-0.250^{\circ} \mathrm{C}$ per decade. Winter maximum temperature in the $\mathrm{PRD}$ region is also increased by urbanization at a rate of $0.076-0.125^{\circ} \mathrm{C}$ per decade.

(5) The urban warming accounts for $12 \%-24 \%$, 36\%$68 \%$ and $20 \%-32 \%$ of the total regional warming, respectively, in the BTH, YRD and PRD regions. Most strikingly, the contribution rate of urban warming in the YRD region is the largest and explains around half of the total regional warming.

As most meteorological stations have been migrated for several times, the homogeneity-adjusted dataset, which could mitigate the impact of subjective factors in observed records, is taken to analyze the SAT change in eastern China in this study. Despite there are a few controversies about the method of homogeneity adjustment, the adjusted data reflects temperature series more objectively. Furthermore, Peterson [19] argued that there was no significant impact of urbanization in observed records once the temperature series were adjusted for homogeneities. However, this study confirmed that an urban warming effect is still remarkable in the homogeneity-adjusted data.

Although the spatial filtering (i.e. MSA) method proposed in this study can detect the spatial heterogeneities of temperature trends on different scales, whether or not the filtered spatial patterns could fully reflect the impact of LUCC on temperature trends still needs to be further examined. Meanwhile, the results can be altered with the expansion of filtering windows, so which scale should be selected to appropriately detect the impact of urbanization also needs to be investigated. Although three scales that are empirically chosen to analyze the spatial heterogeneities of the SAT trends in this study, the spatial patterns displayed for the three scales are substantially consistent, which confirms the effectiveness of the MSA method in identifying the impact of urbanization and other LUCC processes on the SAT change.

Despite a small contribution to the SAT trends in entire eastern China, the urbanization still has considerable influence on the regional climate change. Therefore, a more reasonable urban planning should be considered in order to mitigate regional climate warming. This study also found that the climatic effect of urbanization features obvious temporal-spatial differences, which may be associated with the variation of regional climatic background and the change of anthropogenic heat release. The mechanism responsible for those impacts needs to be further explored in future studies.

The authors would like to thank two anonymous reviewers for their constructive comments and suggestions. The authors also thank Profs. Yan Zhongwei and Tang Jianping, as well as Drs. Li Zhen, Ma Xingye, and Wang Tianyi for their data support and valuable comments. This work was supported by the National Basic Research Program of China (2010CB428504).

1 Intergovernmental Panel on Climate Change. IPCC AR4 Report. Cambridge: Cambridge University Press, 2007

2 Pielke R A. Land use and climate change. Science, 2005, 310: 16251626

3 Jiang D B, Zhang Y, Lang X M. Vegetation feedback under future global warming. Theor Appl Climatol, 2011, 106: 211-227

4 Li X, Yang X Q, Tang J P, et al. Multiple urban heat islands and surface energy balance during summer in Yangtze River Delta city cluster region simulated with WRF/NCAR (in Chinese). J Meteorol Sci, 2011, 31: 441-450

5 Kalnay E, Cai M. Impact of urbanization and land-use change on climate. Nature, 2003, 423: 528-531

6 Wang W C, Zeng Z, Karl T R. Urban heat islands in China. Geophys Res Lett, 1990, 17: 2377-2380 
7 Jones P D, Groisman P Y, Coughlan M, et al. Assessment of urbanization effects in time series of surface air temperature over land. Nature, 1990, 347: 169-172

8 Zhao Z C. The changes of temperature and the effects of the urbanization in China in the last 39 years (in Chinese). Meteor Mon, 1991, 17: $14-17$

9 Portman D A. Identifying and correcting urban bias in regional time series: Surface temperature in China's northern plains. J Clim, 1993, 6: 2298-2308

10 Zhou S Z, Shu J. Urban Climatology (in Chinese). Beijing: Chinese Meteorological Press, 1994. 244-339

11 Easterling D R, Horton B, Jones P D, et al. Maximum and minimum temperature trends for the globe. Science, 1997, 277: 364-367

12 Zhou Y Q, Ren G Y. Identifying and correcting urban bias for regional surface air temperature series of north China over period of 1961-2000 (in Chinese). Climatic Environ Res, 2005, 10: 743-753

13 Fang F, Bai H Z, Zhao H Y, et al. The urbanization effect in northwestern China and its contribution to temperature warming (in Chinese). Plateau Meteorol, 2007, 26: 579-585

14 Ren G Y, Chu Z Y, Chen Z H, et al. Implications of temporal change in urban heat island intensity observed at Beijing and Wuhan stations. Geophys Res Lett, 2007, 34: L05711

15 Ren G Y, Zhou Y Q, Chu Z Y, et al. Urbanization effects on observed surface air temperature trends in North China. J Clim, 2008, 21: $1333-1348$

16 Hua L J, Ma Z G, Guo W D. The impact of urbanization on air temperature across China. Theor Appl Climatol, 2008, 93: 179-194

17 Tang G L, Ren G Y, Zhou J X. Change of urban heat island intensity and its effect on surface mean air temperature records in southwest China (in Chinese). J Appl Meteor Sci, 2008, 17: 722-730

18 Hansen J, Ruedy R, Sato M, et al. A closer look at United States and global surface temperature change. J Geophys Res, 2001, 106: 2394723963

19 Peterson T C. Assessment of urban versus rural in situ surface temperatures in the contiguous United States: No difference found. J Clim, 2003, 16: 2941-2959

20 Du Y, Xie Z Q, Zeng Y, et al. Impact of urban expansion on regional temperature change in the Yangtze River Delta. J Geogr Sci, 2007, 17: 387-398

21 He J F, Liu J Y, Zhuang D F, et al. Assessing the effect of land use/ land cover change on the change of urban heat island intensity. Theor Appl Climatol, 2007, 90: 217-226

22 Yang X C, Hou Y L, Chen B D. Observed surface warming induced by urbanization in east China. J Geophys Res, 2011, 116: D14113

23 Wang F, Ge Q S. Estimation of urbanization bias in observed surface temperature change in China from 1980 to 2009 using satellite landuse data. Chin Sci Bull, 2012, 57: 1708-1715

24 Chu Z Y, Ren G Y. Effect of enhanced urban heat island magnitude on average surface air temperature series in Beijing region (in Chinese). Acta Meteorol Sin, 2005, 63: 534-540

25 Kim M K, Kim S. Quantitative estimates of warming by urbanization in South Korea over the past 55 years (1954-2008). Atmos Environ, 2011, 45: 5778-5783

26 Li Q, Zhang H, Liu X, et al. Urban heat island effect on annual mean temperature during the last 50 years in China. Theor Appl Climatol, 2004, 79: 165-174

27 Li Q X, Li W, Si P, et al. Assessment of surface air warming in northeast China, with emphasis on the impacts of urbanization. Theor Appl Climatol, 2010, 99: 469-478

28 Zhang A Y, Ren G Y, Zhou J X, et al. On the urbanization effect on surface air temperature trends over China (in Chinese). Acta Meteorol Sin, 2010, 68: 957-966

29 Zhou L M, Dickinson R E, Tian Y H, et al. Evidence for a significant urbanization effect on climate in China. Proc Natl Acad Sci USA, 2004, 101: 9540-9544

30 Zhang J Y, Dong W J, Wu L Y, et al. Impact of land use changes on surface warming in China. Adv Atmos Sci, 2005, 22: 343-348

31 Lim Y K, Cai M, Kalnay E, et al. Observational evidence of sensitivity of surface climate changes to land types and urbanization. Geophys Res
Lett, 2005, 32: L2271222

32 Nuñez M N, Ciapessoni H H, Rolla A, et al. Impact of land use and precipitation changes on surface temperature trends in Argentina. J Geophys Res, 2008, 113: D06111

33 Yang X C, Zhang Y L, Liu L S, et al. Sensitivity of surface air temperature change to land use/cover types in China. Sci China Ser D: Earth Sci, 2009, 52: 1207-1215

34 Fall S, Niyogi D, Gluhovsky A, et al. Impacts of land use land cover on temperature trends over the continental United States: Assessment using the North American Regional Reanalysis. Int J Climatol, 2010, 30: 1980-1993

35 Hu Y C, Dong W J, He Y. Impact of land surface forcings on mean and extreme temperature in eastern China. J Geophys Res, 2010, 115: D19117

36 Sun M, Tang J P, Xu C Y. Impact of urbanization and land-use change on regional temperature in eastern China (in Chinese). J Nanjing Univ Nat Sci, 2011, 47: 679-691

37 Trenberth K E. Climatology (communication arising): Rural land-use change and climate. Nature, 2004, 427: 213

38 Vose R S, Karl T R, Easterling D R, et al. Climate (communication arising): Impact of land-use change on climate. Nature, 2004, 427: 213-214

39 Zhang L, Yang X Q, Tang J P, et al. Simulation of urban heat island effect and its impact on atmospheric boundary layer structure over Yangtze River Delta region in summer (in Chinese). J Meteorol Sci, 2011, 31: 431-440

40 Ding Y H, Dai X S. Temperature change during the recent 100 years over China (in Chinese). Meteorol Mon, 1994, 20: 19-26

41 Li Q X, Liu X N, Zhang H Z, et al. Detecting and adjusting temporal inhomogeneity in Chinese mean surface air temperature data. Adv Atmos Sci, 2004, 21: 260-268

42 Li Q X, Dong W J. Detection and adjustment of undocumented discontinuities in Chinese temperature series using a composite approach. Adv Atmos Sci, 2009, 26: 143-153

43 Li Z, Yan Z W. Homogenized daily mean/maximum/minimum temperature series for China from 1960-2008. Atmos Oceanic Sci Lett, 2009, 2: 236-242

44 Li Z, Yan Z W. Application of multiple analysis of series for homogenization to Beijing daily temperature series (1960-2006). Adv Atmos Sci, 2010, 27: 777-787

$45 \mathrm{Wu} \mathrm{Z}$ X. Preliminary analysis of the information on meteorological station historical evolution and its impacts on homogeneity of observational records (in Chinese). J Appl Meteorol Sci, 2005, 16: 461-467

46 Li Q X, Liu X N, Zhang H Z, et al. Homogeneity study of in situ observational climate series (in Chinese). Meteorol Sci Technol, 2003, 31: $3-10$

47 Wu L H, Kang L L, Chen H Y, et al. Effect of meteorological observation environment variability on homogeneity of temperature series in Zhejiang Province (in Chinese). Meteorol Sci Technol, 2007, 35: $152-156$

48 Cao L J, Yan Z W. Progresses in research of homogenization of climate data (in Chinese). Adv Clim Change Res, 2011, 7: 129-135

49 He C Y, Shi P J, Li J G, et al. Restoring urbanization process in China in the 1990s by using non-radiance-calibrated DMSP/OLS nighttime light imagery and statistical data. Chin Sci Bull, 2006, 51: 1614-1620

50 Wang H R, Zheng X Q, Yuan T. Overview of researches based on DMSP/OLS nighttime light data (in Chinese). Progr Geogr, 2012, 31: $11-19$

51 He C Y, Li J G, Chen J, et al. The urbanization model and process in Bohai sea surrounding area in the 1990s by using DMSP/OLS data (in Chinese). Acta Geogr Sin, 2005, 60: 409-417

52 Shu S, Yu B L, Wu J P, et al. Methods for deriving urban built-up area using night-light data: Assessment and application (in Chinese). Remote Sens Technol Appl, 2011, 26: 169-176

$53 \mathrm{Xu} \mathrm{M} \mathrm{J,} \mathrm{Chen} \mathrm{L,} \mathrm{Liu} \mathrm{H} \mathrm{J,} \mathrm{et} \mathrm{al.} \mathrm{Pattern} \mathrm{and} \mathrm{process} \mathrm{of} \mathrm{urbanization} \mathrm{in}$ the Yangtze Delta based on DMSP/OLS data (in Chinese). Remote Sens Land Resour, 2011, 3: 106-112

54 Ding Y H, Ren G Y, Zhao Z C, et al. Detection, causes and projection of climate change over China: An overview of recent progress. 
Adv Atmos Sci, 2007, 24: 954-971

55 Chen B, Shi G Y, Dai T, et al. Climate forcing due to anthropogenic heat release over China (in Chinese). Clim Environ Res, 2011, 16: 717-722

56 Zhang C, Shu J, Chen S S. Urban anthropogenic heat categorizing and its effects on urban temperature (in Chinese). Resour Environ Yangtze Basin, 2011, 20: 232-238

57 Zhang Y, Bao W J, Yu Q, et al. Study on seasonal variations of the urban-heat island and its interannual changes in a typical Chinese megacity (in Chinese). Chin J Geophys, 2012, 55: 1121-1128

58 Hua L J. An analysis of the temperature range and the warming effect of urbanization in China regions (in Chinese). Dissertation for the Doctoral Degree. Qingdao: Ocean University of China, 2004. 22-43

59 Ji C P, Liu W D, Xuan C Y. Impact of urban growth on the heat island in Beijing (in Chinese). Chin J Geophys, 2006, 49: 69-77

60 Zhang J H, Meng Q W, Li X, et al. Urban heat island variations in Beijing region in multi spatial and temporal scales (in Chinese). Sci Geogr Sin, 2011, 31: 1349-1354

Open Access This article is distributed under the terms of the Creative Commons Attribution License which permits any use, distribution, and reproduction in any medium, provided the original author(s) and source are credited. 